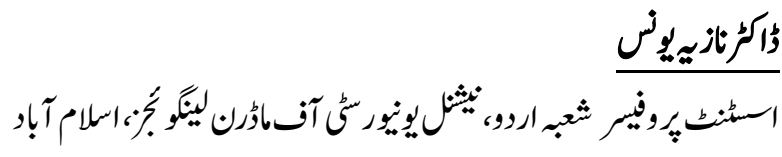

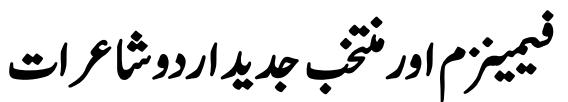

Dr. Nazia Younis

Assistant Professor, National University of Modern Languages, NUML Islamabad.

\title{
Feminism and Modern Urdu Poetess
}

Urdu literature has a rich and prestigious tradition of poetery. The contribution of poetess is a great contribution in this tradition. The discision of Feminism is some how new and relevant in the literary circles. The outstanding and exemplary role of Urdu poetess is a fantastic job. It is necessary to highlight the services of those poetess, who are currently working for this case.This article has a aim to bring to light their introduction and their services in this regard.The modern Urdu poetess played a vital role in the movement of feminism in the India and as well as in Pakistan.

Keywords: Feminism, Vrdu poetess, introduction, visions, Contributions, Research Articles, Women, Literature.

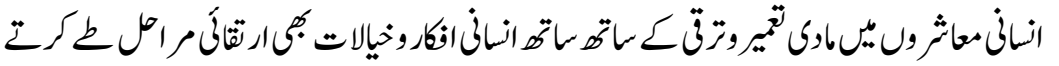

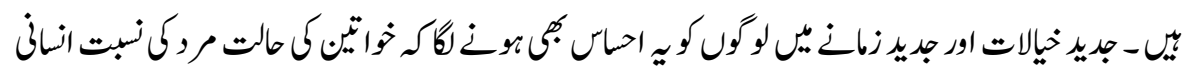

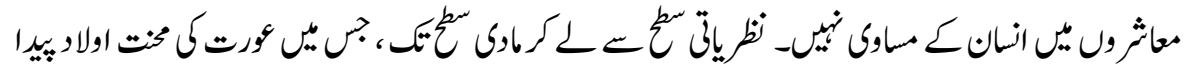

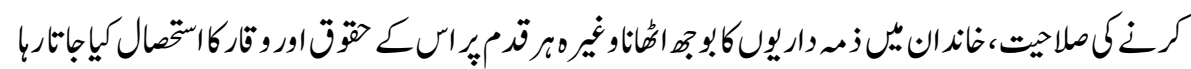

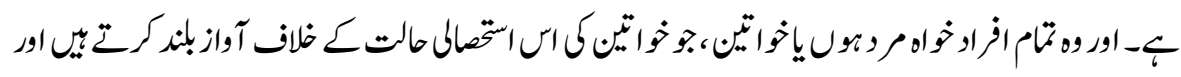

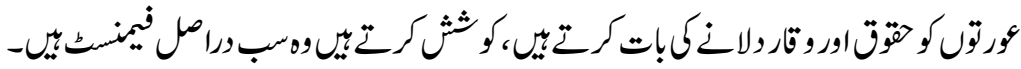

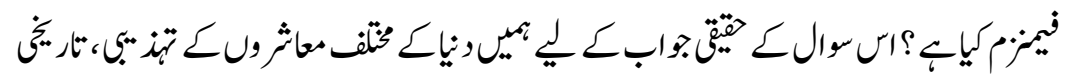

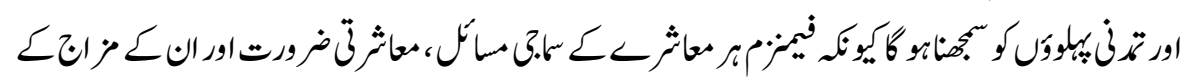

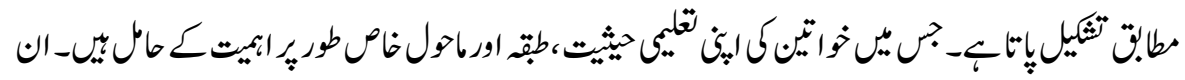




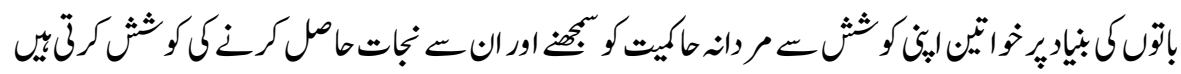

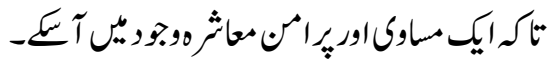

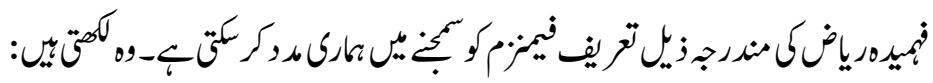

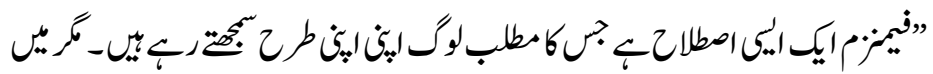

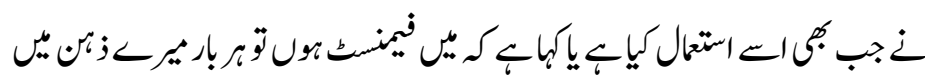

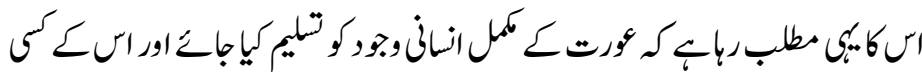

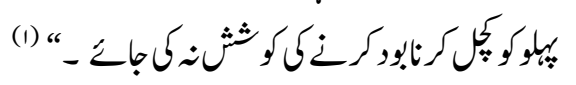

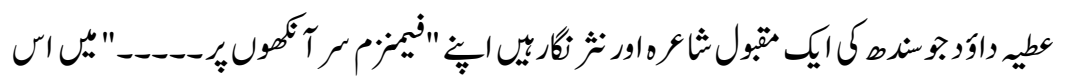

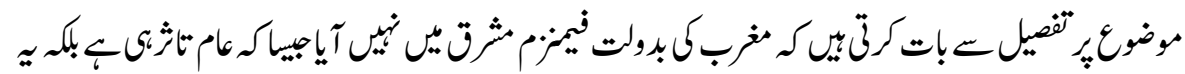

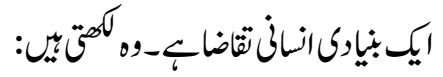

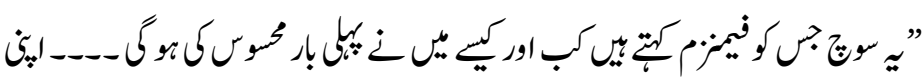

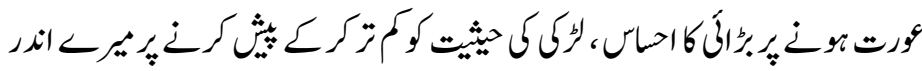

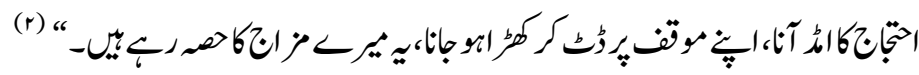

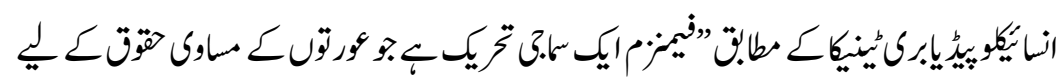

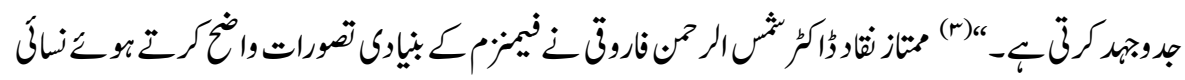

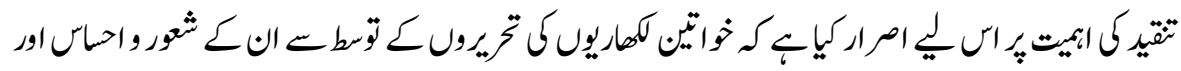

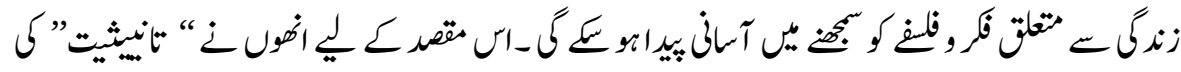

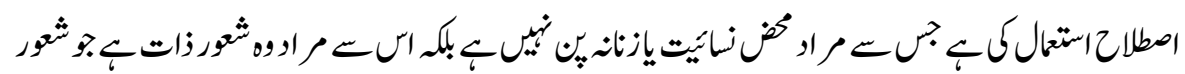

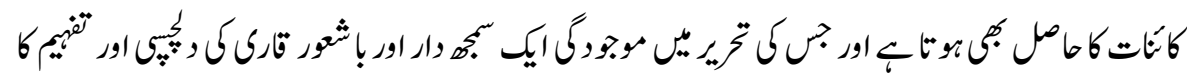
بابث نبتئ

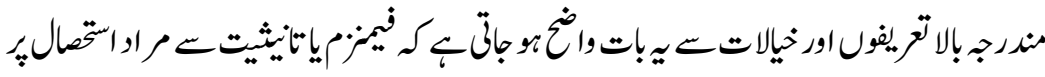

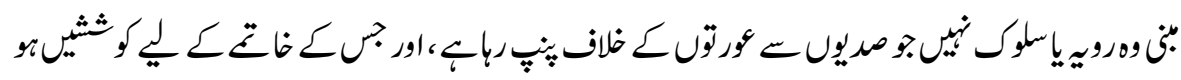

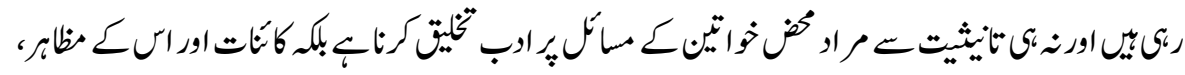




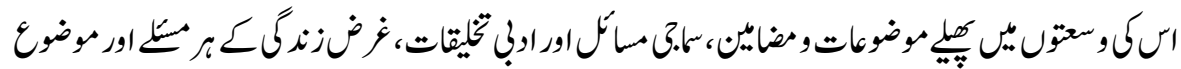

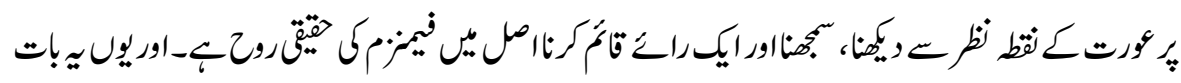

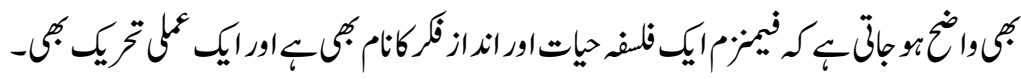

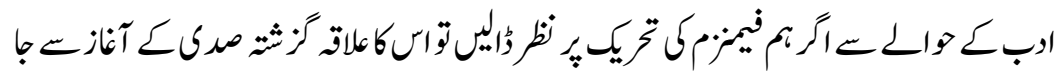

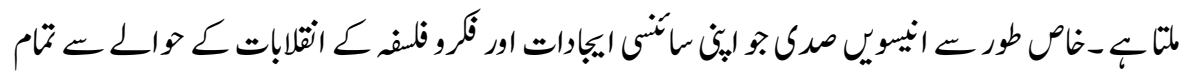

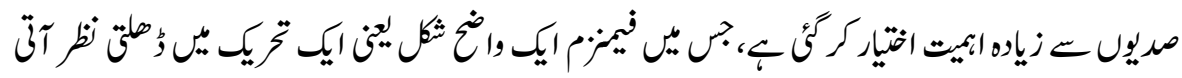

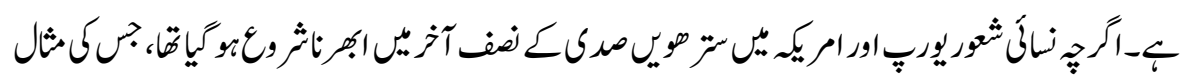

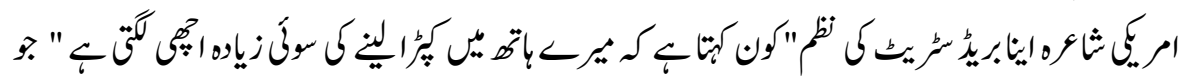

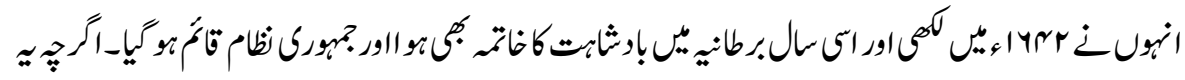

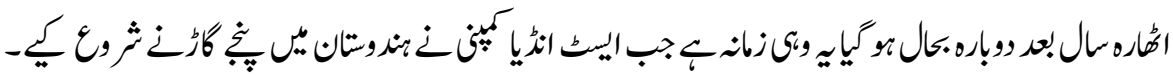

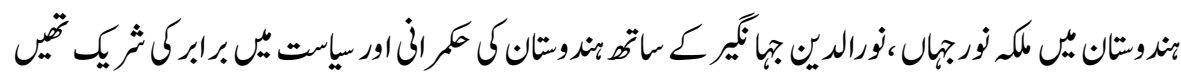

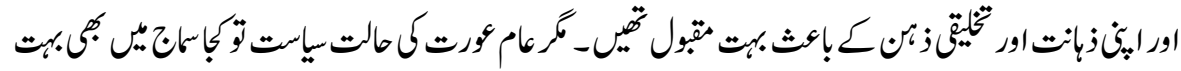

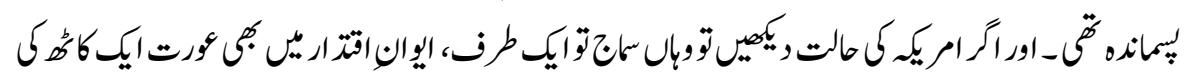

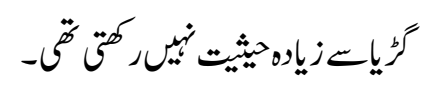

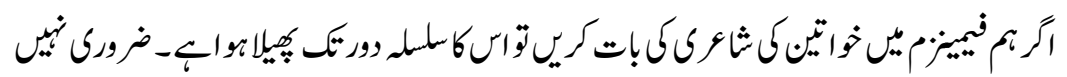

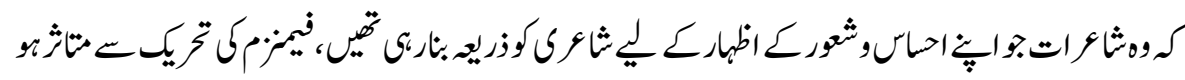

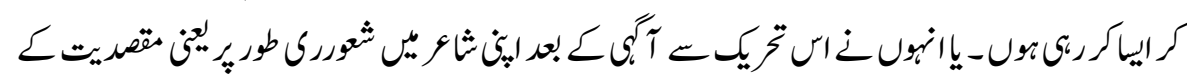

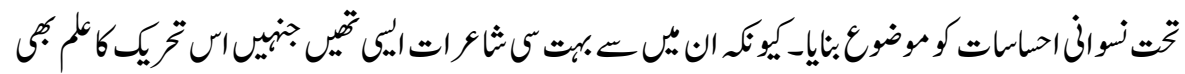

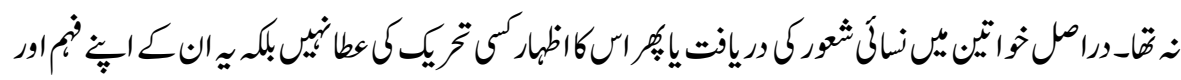

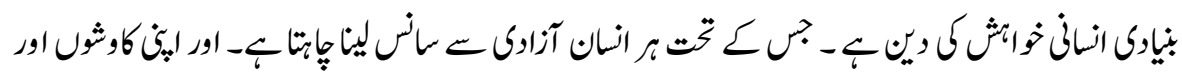

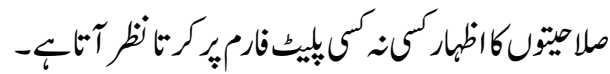

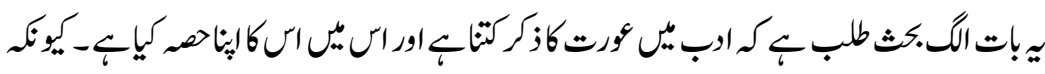

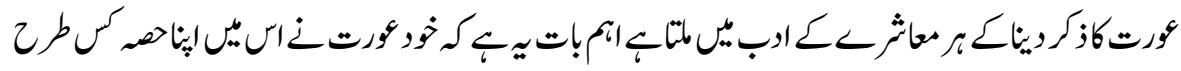




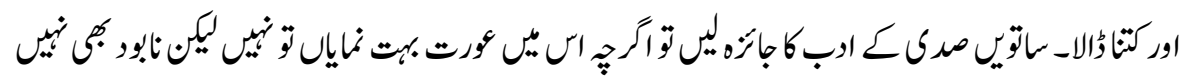

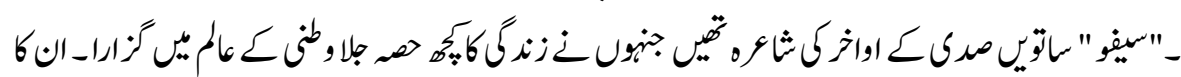

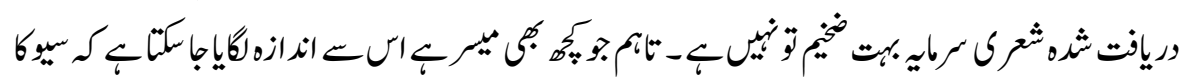

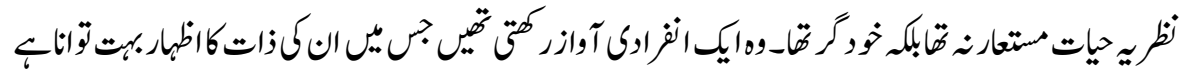

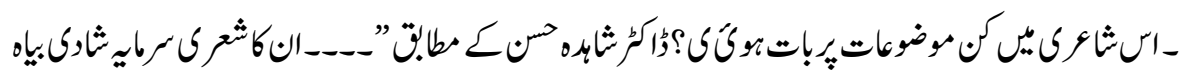

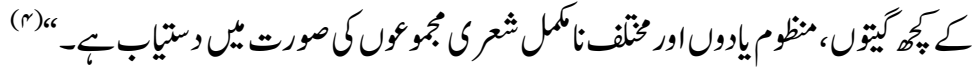

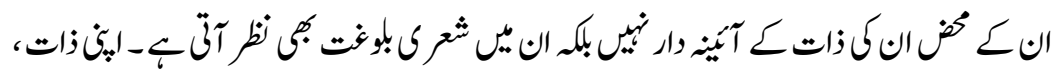

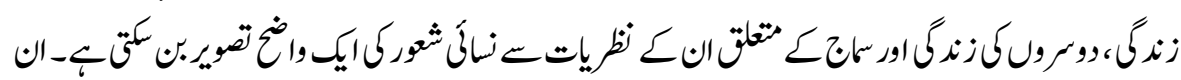

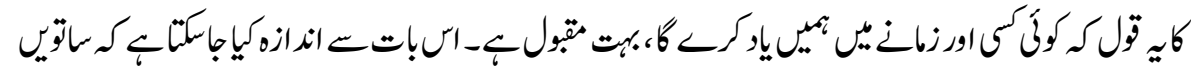

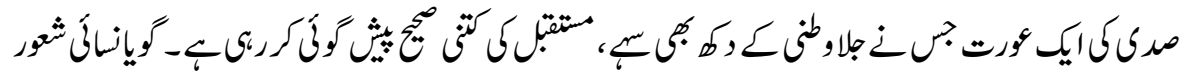

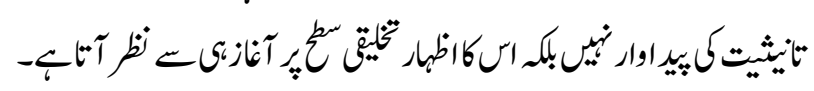

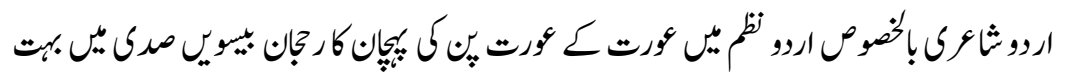

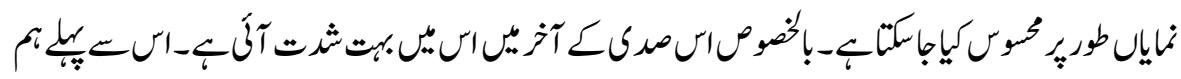

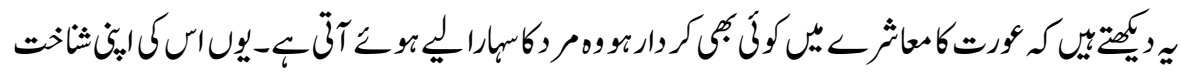

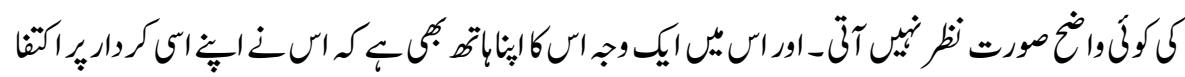

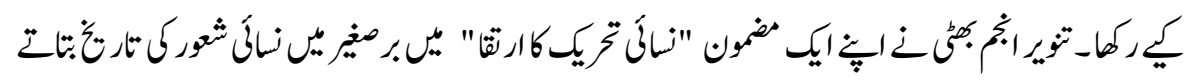

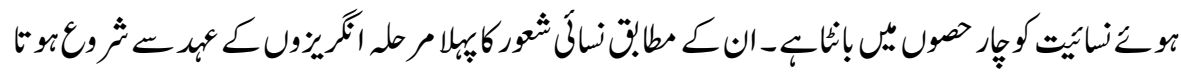

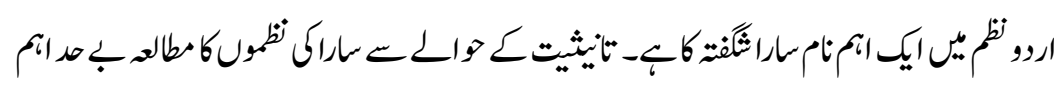

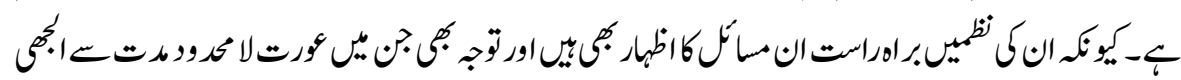

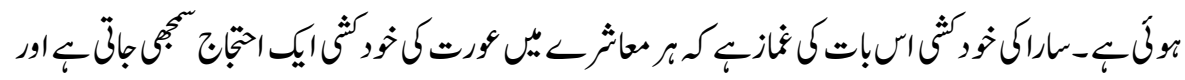

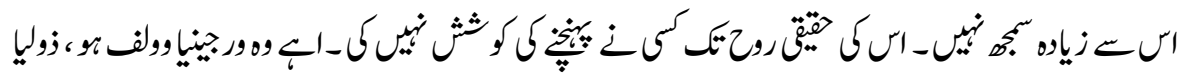

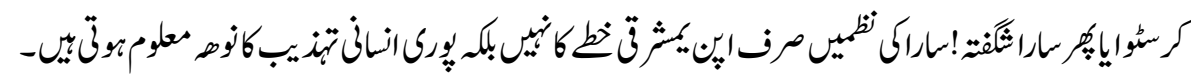




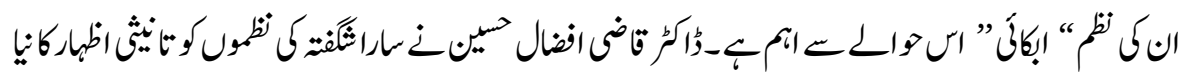

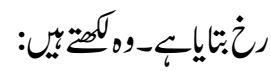

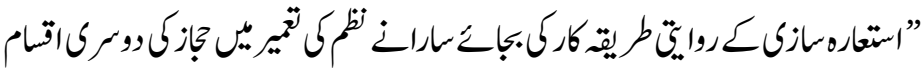

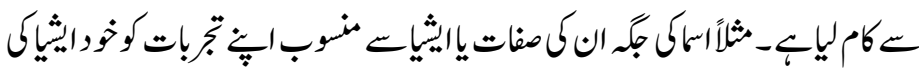

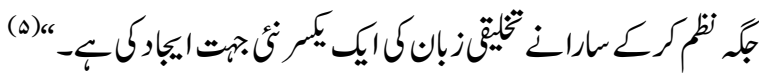

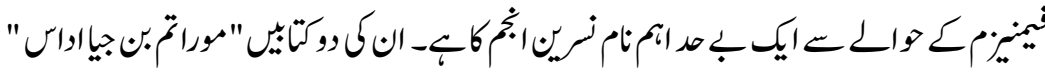

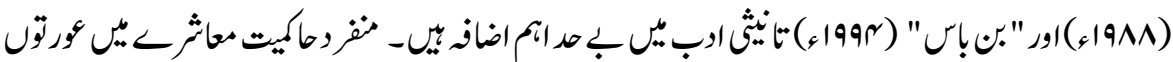

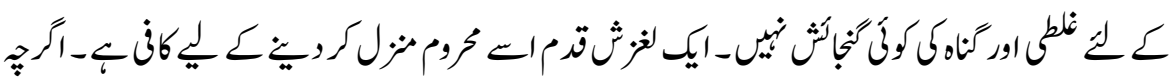

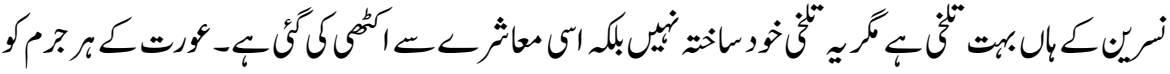

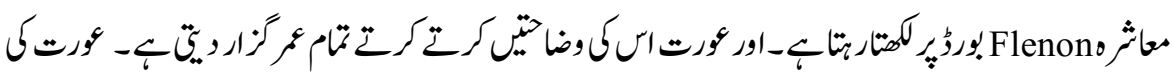

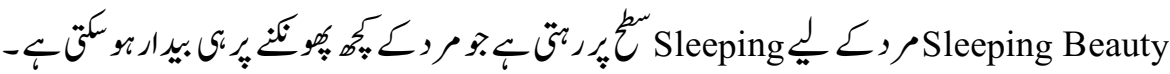

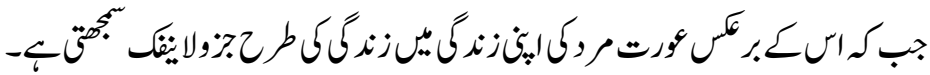

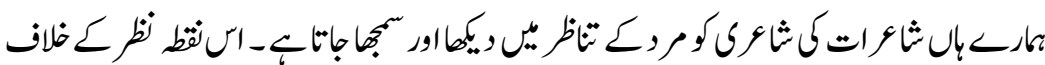

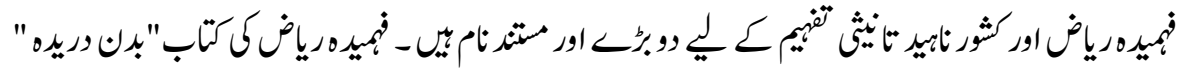

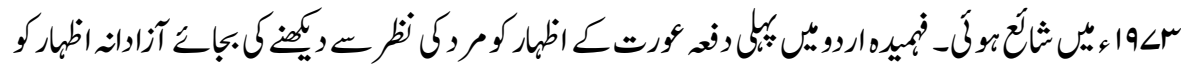

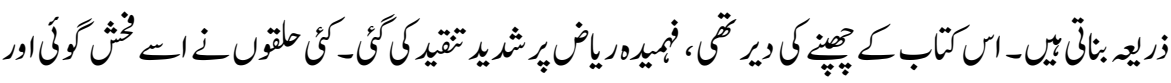

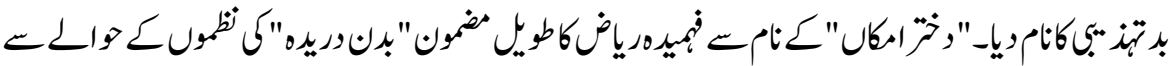

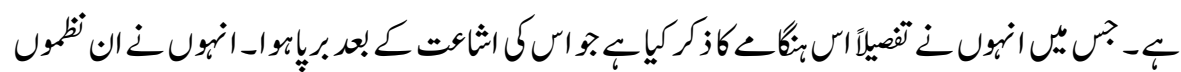

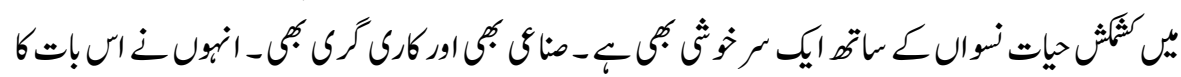

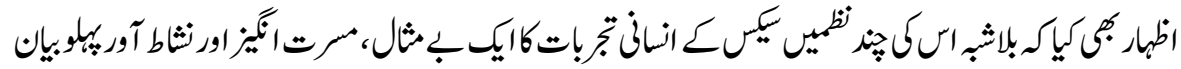

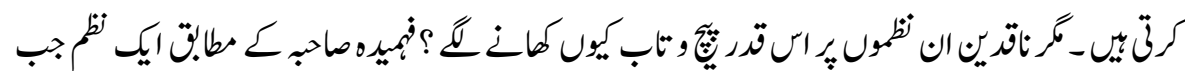

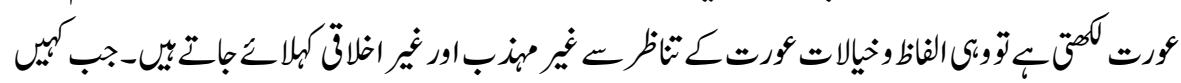

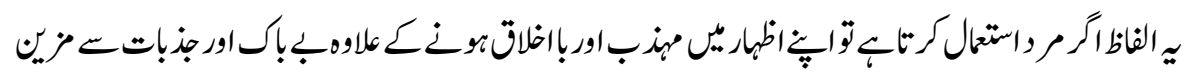




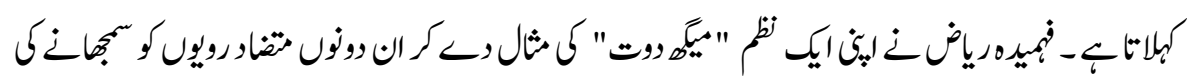

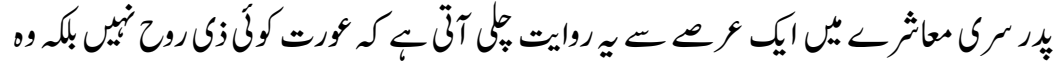

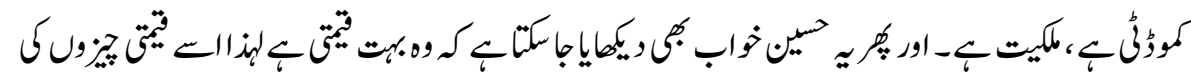

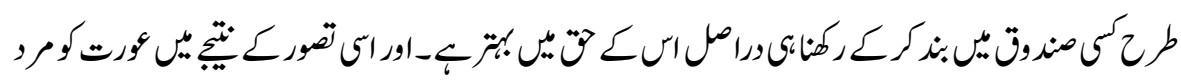

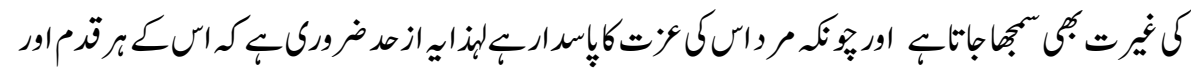

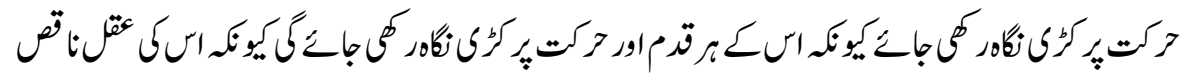

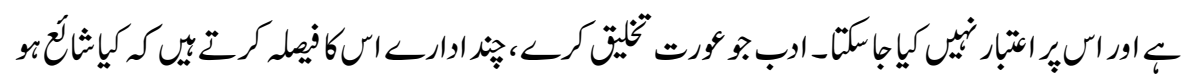

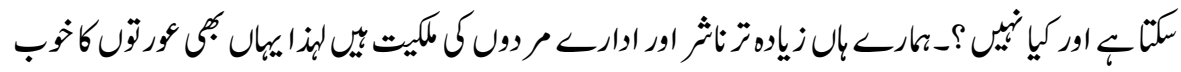

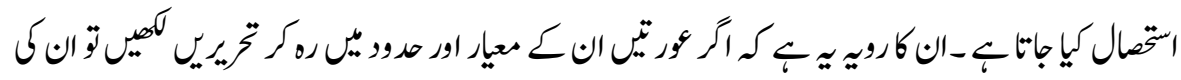

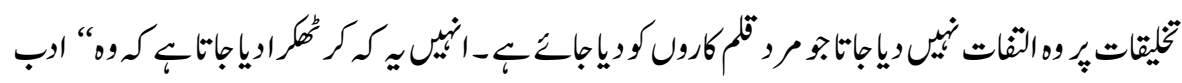

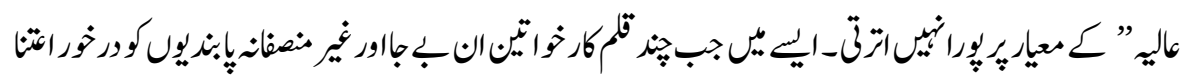

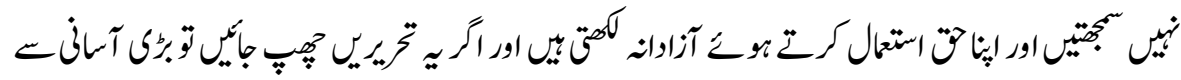

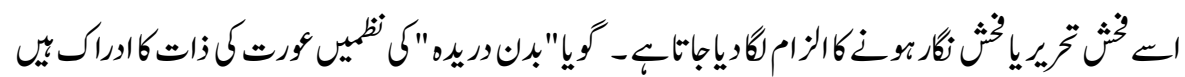

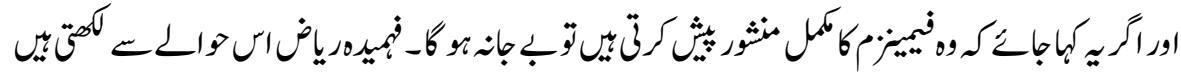

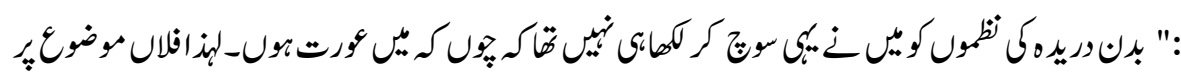

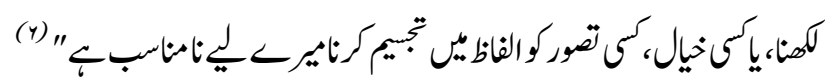

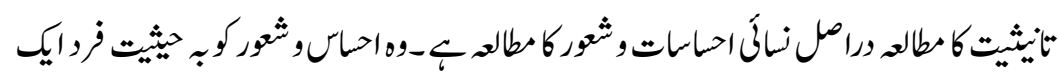

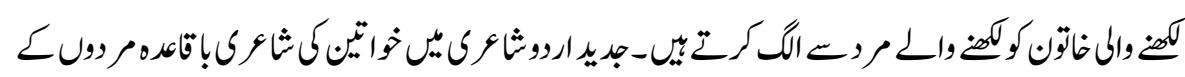

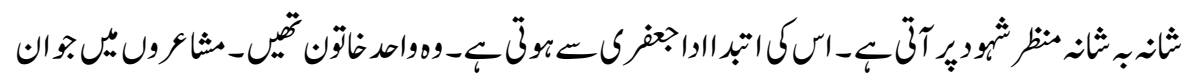

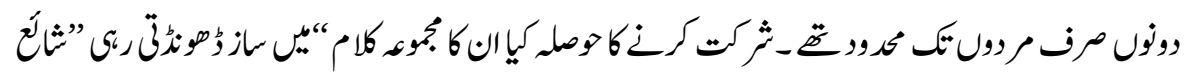

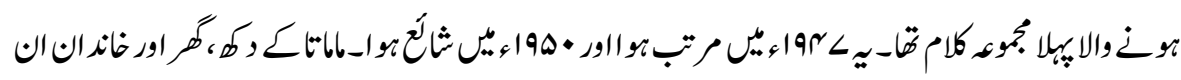

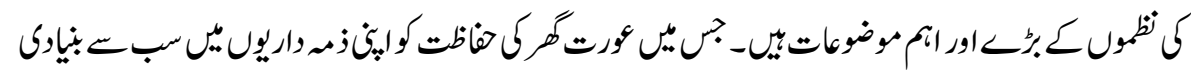




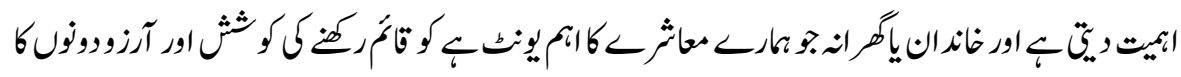
تواتناظهار نظر آثابح-

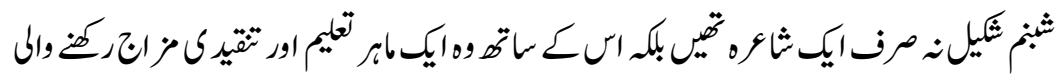

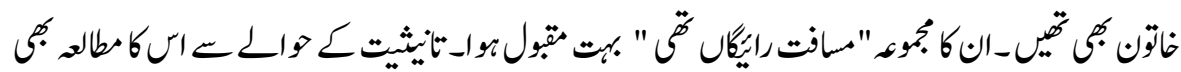

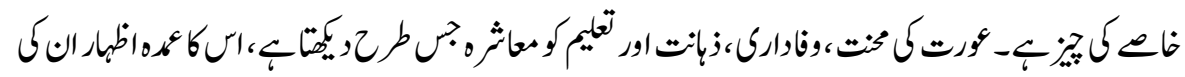

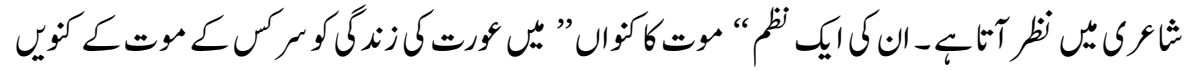

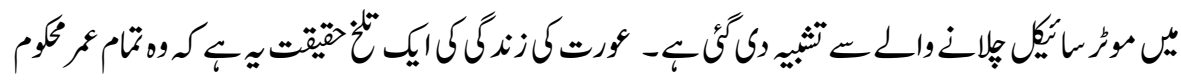

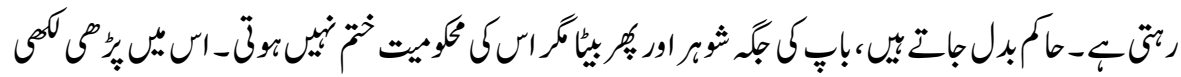

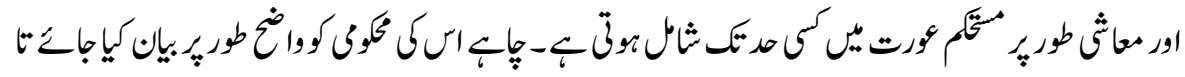

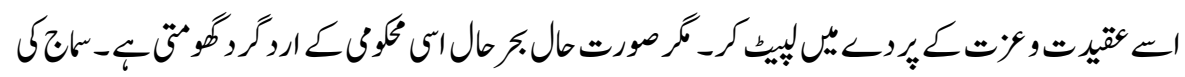

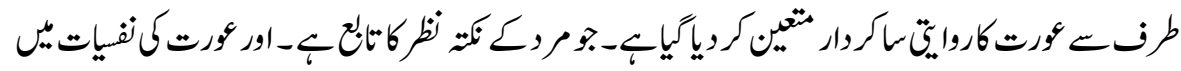

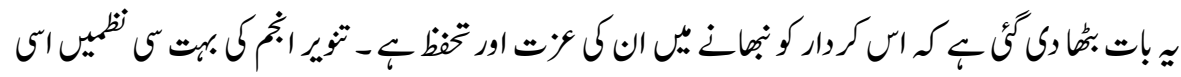

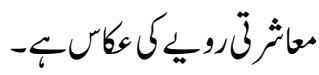

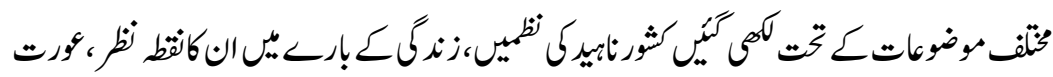

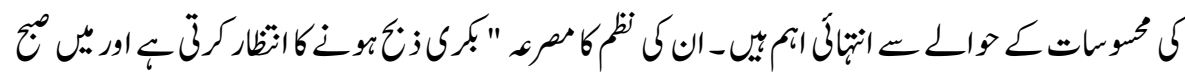

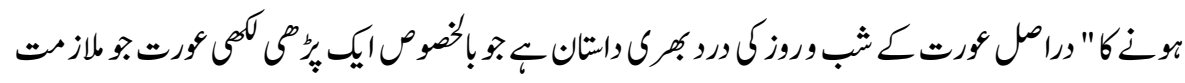

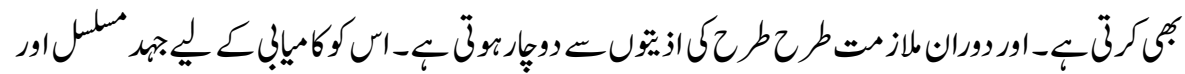

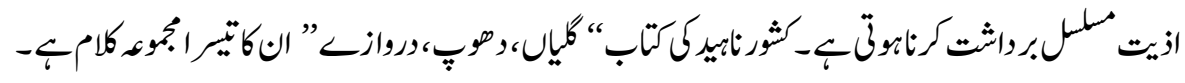

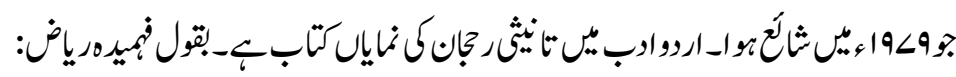

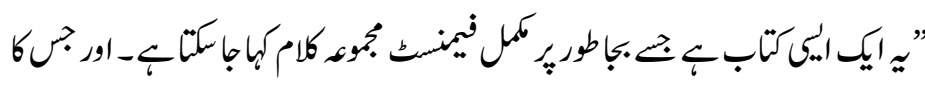

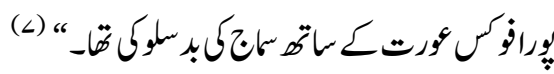

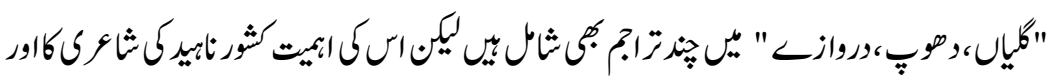

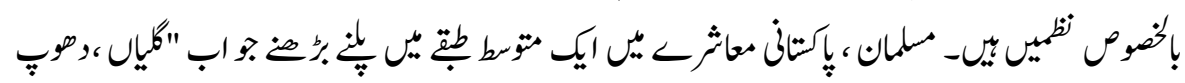


ISSN (Print): 2709-9636 | ISSN(Online) : 2709-9644 | ISSN-L : 2709-9636

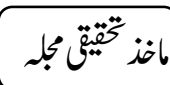

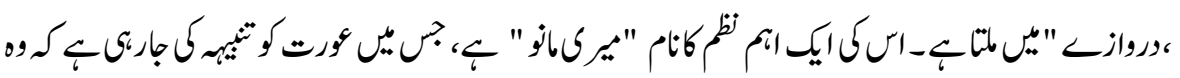

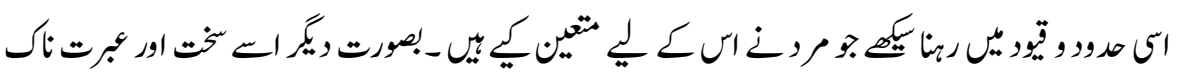

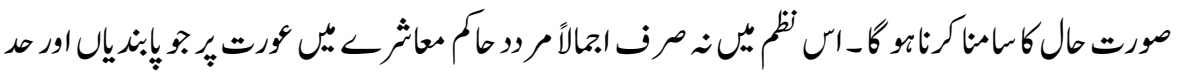

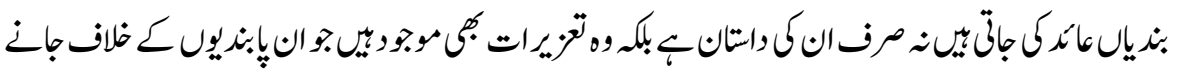

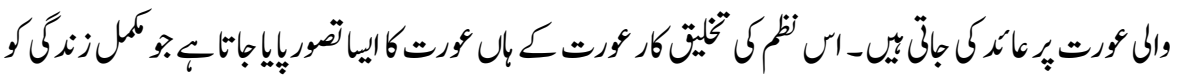

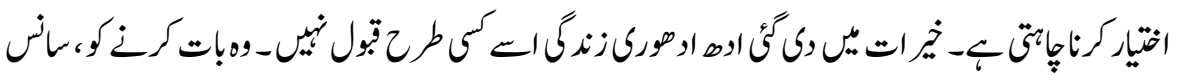

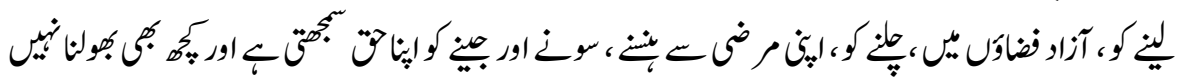

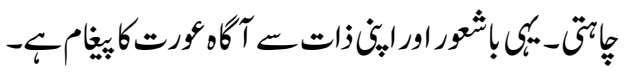

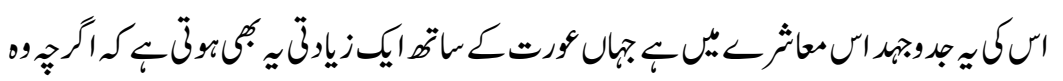

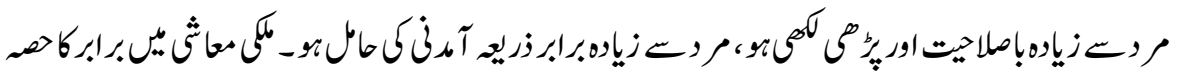

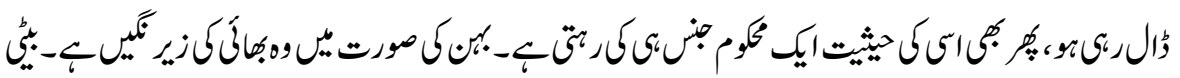

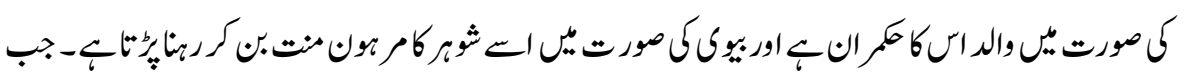

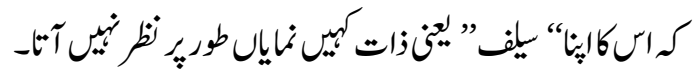

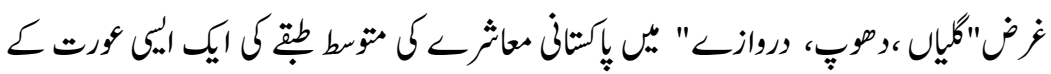

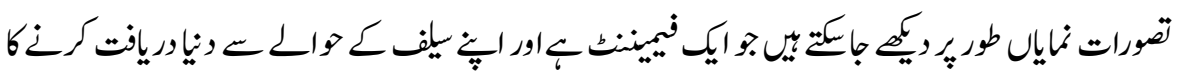

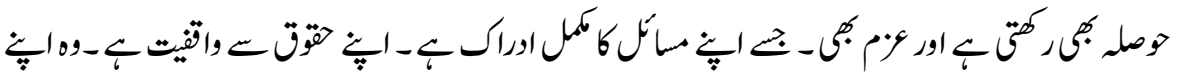

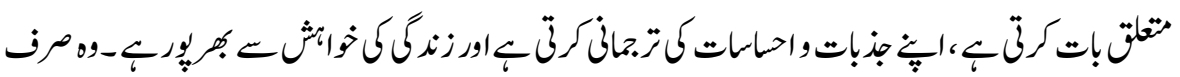

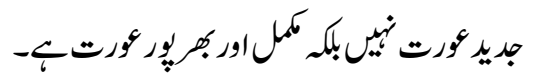

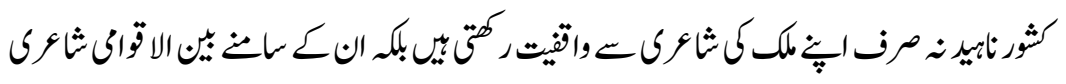

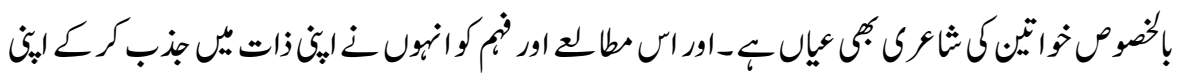

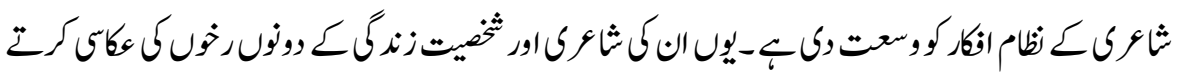

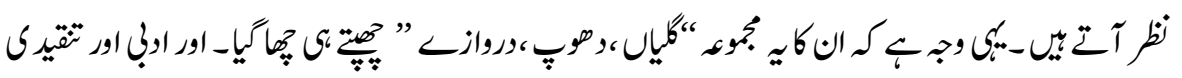

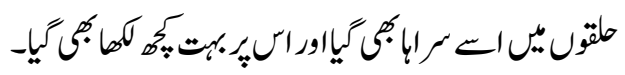

$14 \cdot$ 


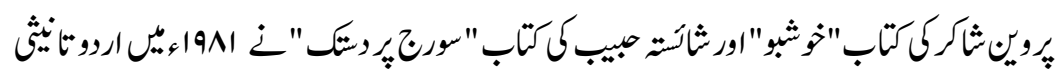

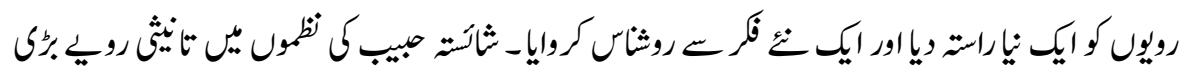

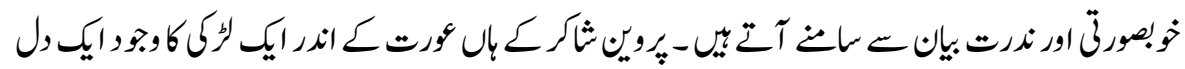

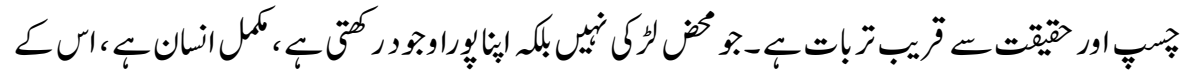

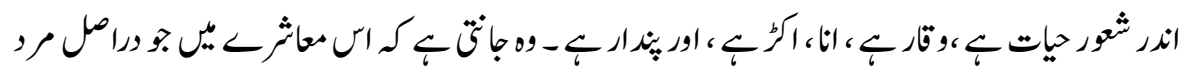

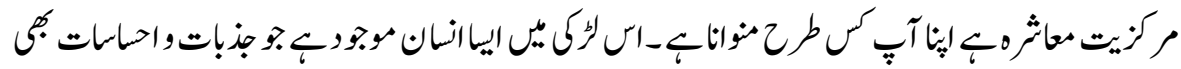

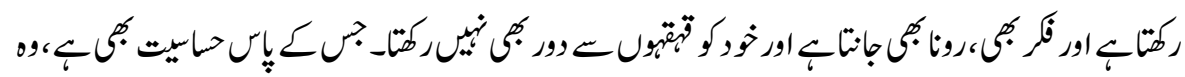

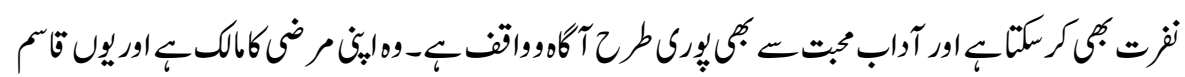

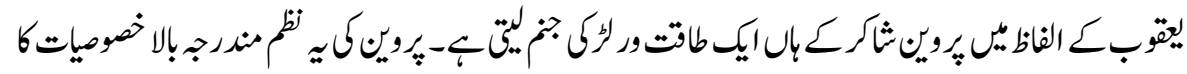

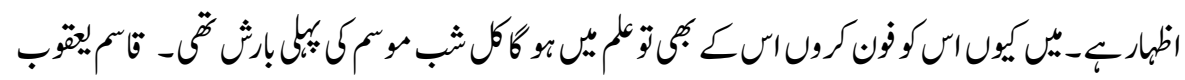

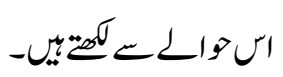

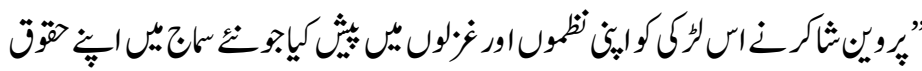

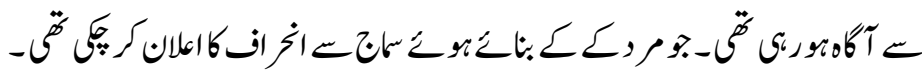

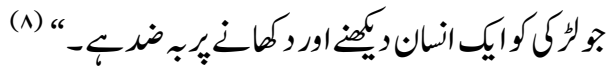

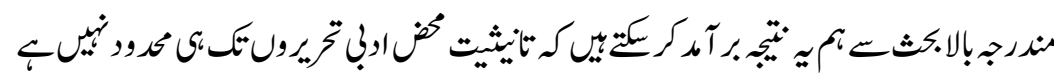

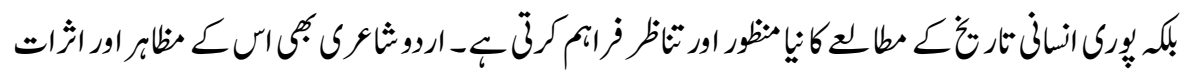

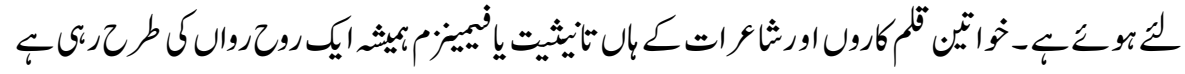

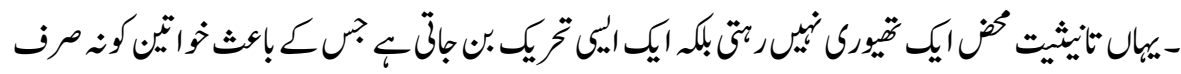

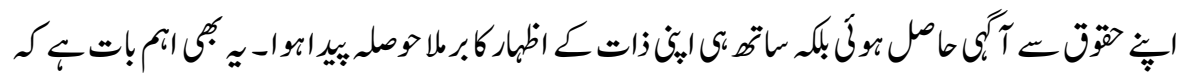

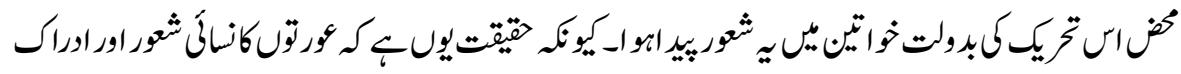

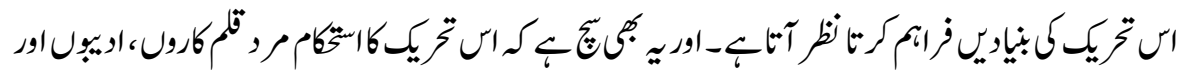

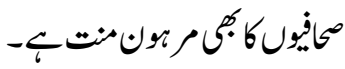


ISSN (Print): 2709-9636 | ISSN(Online) : 2709-9644 | ISSN-L : 2709-9636

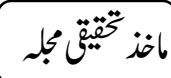

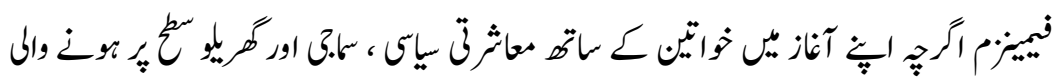

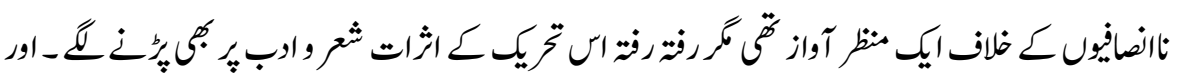

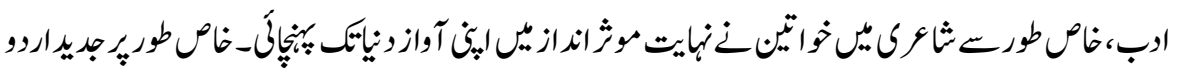

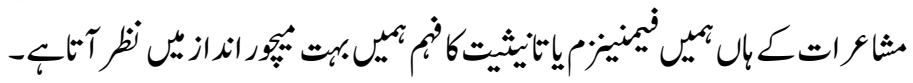

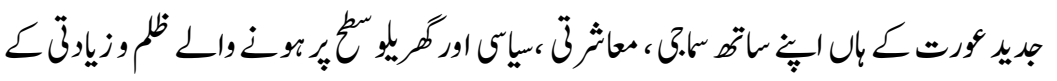

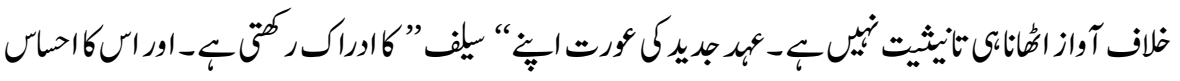

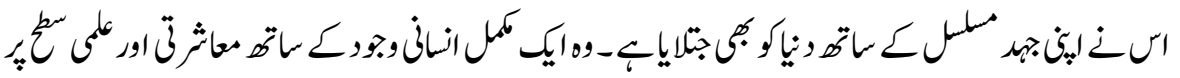

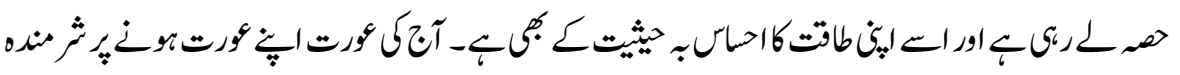

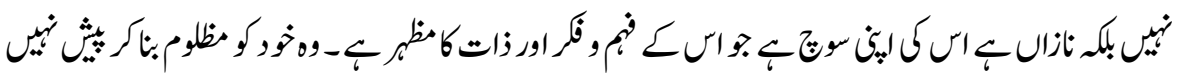

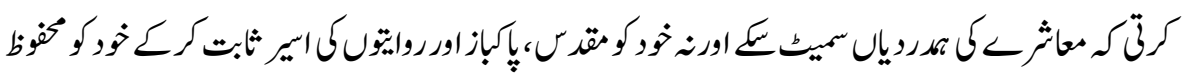

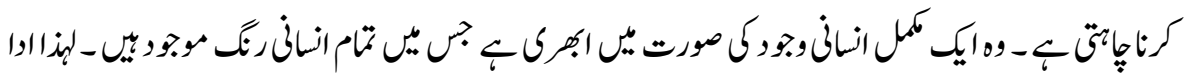

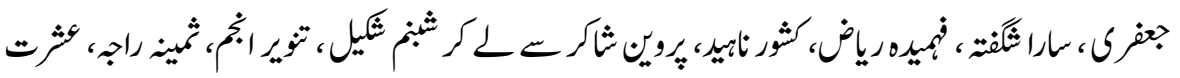

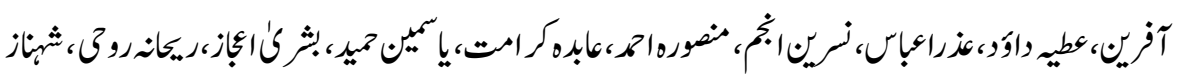

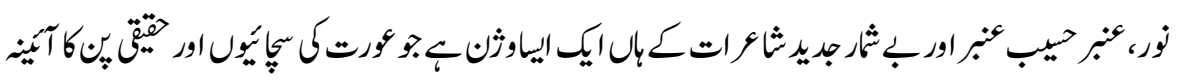

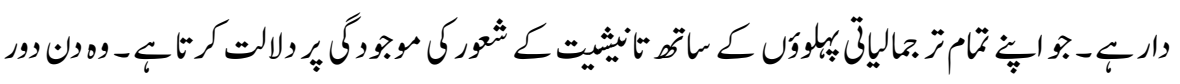

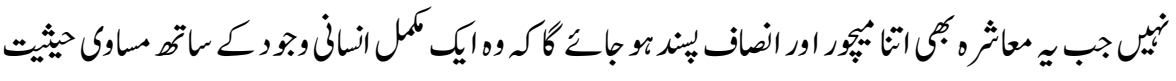

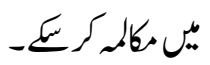

والرجات

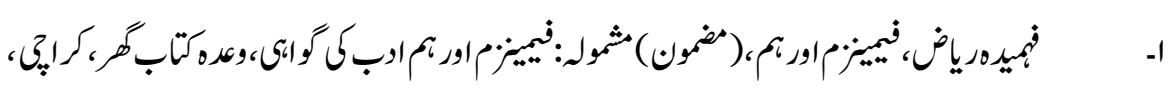

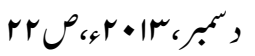
r

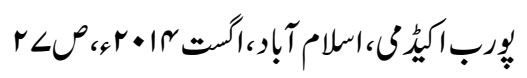

INM 
ISSN (Print): 2709-9636 | ISSN(Online) : 2709-9644 | ISSN-L : 2709-9636

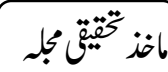

Britiannica Concise Encylopedia http://www. $\quad-\mu$

Britannica.com/feminism retrieved on 27/11/2008

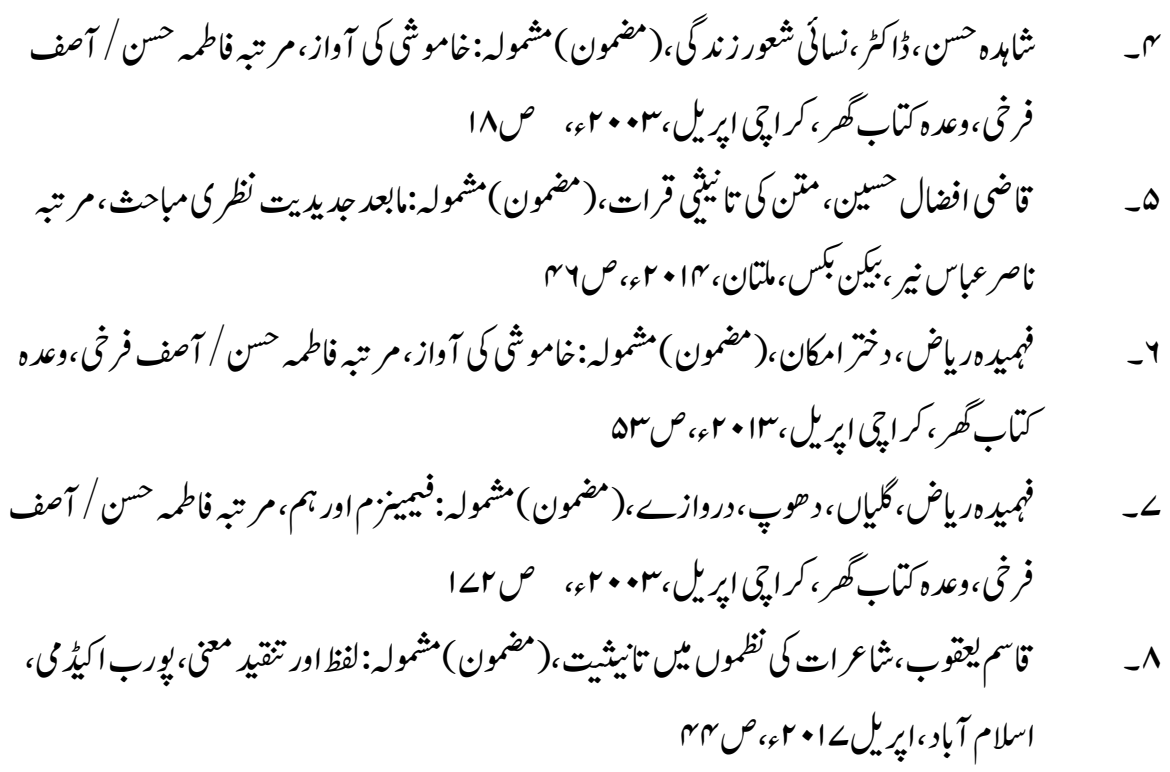

$1 N M$ 